\title{
An economic analysis of fig in Pune district of Maharashtra
}

\author{
K. S. DAUNDKAR, U.S. BONDAR, SUPRIYA D. KASHID AND H.P. THAKARE
}

Received : 19.07.2016; Revised : 16.08.2016; Accepted : 03.09.2016

\begin{abstract}
An attempt has been made to estimate resource use, cost, returns, profitability and to identify the problems faced by sample fig grower in production of fig in Pune district. Keeping in view the highest acerages under fig, Purandar and Bhor tahsils from Pune district were purposefully selected. Eight villages viz., Zendewadi, Dive, Rajewadi, Kalewadi, Soneri, Pimple, Velu and Shindewadi were selected. Five cultivars each from small, medium and large size groups from these eight villages selected randomly. Thus, the total samples of 120 fig grower were selected for study. The primary data collected for the agriculture year 2012-13 were analyzed by using simple tabular method in fig cultivation. The per hectare cost of establishment was Rs. $70,9,38.21$. The major items of cost were cost on account of manures and manuring, interculturing, fertilizer, interest on fixed capital and cutting. The annual per hectare cost of cultivation of fig was Rs. 1,48,096.70 of which cost 'A' and cost 'B' constituting 54.93 per cent and 77.46 per cent, respectively. The major problems faced by grower in production of fig were non- availability of labour, high charges of digging pits.
\end{abstract}

KEY WORDS : Economics of production, Cost of cultivation, Problems

How to cite this paper : Daundkar, K.S., Bondar, U.S., Kashid, Supriya D. and Thakare, H.P.(2016). An economic analysis of fig in Pune district of Maharashtra. Internat. J. Com. \& Bus. Manage, 9(2) : 134-140, DOI: 10.15740/HAS/IJCBM/9.2/134-140. 